\title{
Development of Social Welfare Architectures in Marginal Areas of Sub-Saharan Africa. The Case Study of the Gamba Deve-Licoma Axis in Mozambique
}

\section{Domenico Chizzoniti, Monica Moscatelli and Letizia Cattani}

\begin{abstract}
The research concerns a strategic project designed to implement a service supplying system to rural areas of Sub-Saharan Africa through testing of cultural and social welfare architectures that meet the principles of local building and representation principles and the versatility and contextual characteristic of the site. The study analyses a possible approach that may be generalised for use in other contexts featuring high social marginalisation, focusing on rural areas crossed by the street axis Gamba Deve-Licoma in Mozambique.
\end{abstract}

Keywords Sub-Saharan Africa $\cdot$ Typological and figurative aspects $\cdot$ Social welfare structures $\cdot$ Prototype

\section{Introduction}

This essay is part of an experimental research project carried out by the Architectural Design Laboratory-(ADL), ${ }^{1}$ coordinated by Domenico Chizzoniti, started with an

\footnotetext{
${ }^{1} \mathrm{~A}$ facility dealing primarily with research has supported all the department's architectural design activities at the various application scale. A wide range of research activities in the descriptive experimentation for the critical modelling of the architectural space related to the composition's discipline have been undertaken. In this area, several studies are underway in collaboration with other Italian and foreign research partner institutions. Research is ongoing on prototyping of emerging facilities in poor and marginalised contexts in partnership with Not-For-Profit organisations and associations to prepare experimental building models with social welfare functions. Website: http:// www.abc.polimi.it/it/laboratorio-dabc/adl-architectural-design-laboratory/.
}

D. Chizzoniti $(\varangle)$

Architecture, Built Environment and Construction Engineering-ABC Department, Politecnico di Milano, Milan, Italy

e-mail: domenico.chizzoniti@polimi.it

M. Moscatelli

Lecco, Italy

L. Cattani

Fidenza, Italy 
expression of interest from doctors with Africa Cuamm organisation in 2012. Following contact with the Department of Civil, Environmental and Mechanical Engineering-DICAM at University of Trento about the Gamba Deve-Licoma axis, the proposal has been deepened through a social and cultural integrated service system in the architectural design in developing countries laboratory coordinated by Letizia Cattani with Monica Moscatelli.

The objective of the following research project is to design an architectural prototype able to respond to medical, social and humanitarian emergencies in countries struck by natural disasters, war and situations of poverty. Currently, in the migratory emergency phenomena involving European contexts, just as in Third World countries, the provision of essential services and support, in terms of health care and food and water supplies, is entrusted to government organisations and NGOs such as the World Health Organization (WHO), International Bank of Reconstruction and Development (IBRD) and the United Nations International Children's Emergency Fund (UNICEF), committed to responding to emergencies relating in particular to weaker groups at high risk of marginalisation, primarily women and children.

Under these circumstances, the structure in place today is based on building criteria and methods that suffer due to their precarious, transitory and temporary nature. This feature, particularly to temporary works (from tents to mobile structures), makes them unable to cope with the development of emergency conditions so that they can only work for a short and limited period of time. The development and stability of irregular migration and especially the continual changes to admission processes and policies, not only in European countries, call for a practical reflection on how to support the social and health conditions of some emergency situations with a high rate of marginalisation.

The specific aim of this project was, therefore, to establish guidelines for a new emergency-equipped system (health, social and welfare) capable of meeting specific typological, representational and local construction requirements. The configuration of a system with such characteristics was operationally oriented by on the conceptualisation of the prototype and designed to evolve over time, adding to modular elements to the minimum unit depending on the application site and other parameters, such as climate, the local materials and user needs (Chizzoniti et al. 2014).

The guidelines for definition of the prototype are based on certain principles such as functional independence, so that each part of the prototype may be perceived as autonomous and used for different functions; flexibility and adaptability to achieve a system that can be composed in many different ways, creating different spaces for different functions (Falasca 2000); ease of transport to ensure the reversibility of the prototype so that it can be easily reconfigured and transported in suitable containers by water or on land; the aggregative abilities to permit assembly with other modules, resulting in various combinations; finally, ease of construction for manufacture of a 
product in which each individual part must be very light and made from insulating materials, heat and wear-resistant and easily reproducible materials (Novi 1994).

\section{The Case Study of the Gamba Deve-Licoma Axis}

Among the many responses associated with the emergencies, this research focuses on social welfare assistance in a rural district of Sub-Saharan Africa, and in particular, along an axis of primary importance in the district of Caia in Mozambique, known as the Gamba Deve-Licoma axis.

The research conducted by the DICAM at University of Trento ${ }^{2}$ was our starting point for configuring a prototype system through appropriate examination of the types of building, the distribution choices and the figurative characters and the construction choices characteristic of the local culture.

Based on the design guidelines provided by the PDUT Plano de Uso da Terra (District Land Use Plan) and the main territorial planning tool used in the Caia district, in the centre of Mozambique, drafted between 2011 and 2012, the research aims to address a specific aspect of the more general topic of medical and social emergencies, by analysing the main infrastructural axis in this setting, the Estrada Distrital No. 1 (ED1), which connects the centre of Gamba Deve to the east, with Licoma to the west (Fig. 1).

In close proximity to this route, approximately $45 \mathrm{~km}$ in length, small groups of building units are distributed. Within these, there is an insufficient and irregular allocation of services such as markets, mills, small health centres, schools and wells, which are entirely inadequate to meet the requirements of the population. The aim of this research is to identify a coordinated system of small interventions using existing resources as the main force of a development that recognise, in architectural identity, first and foremost, the building factor.

The latter is traditionally based on a population that is distributed according to its needs and possibilities, in Vilas, provision centres for the most important services and administrative sites; in the povoados, small community centres organised mainly around primary services (the well or the school) and, finally, in mudzi, singlefamily buildings located a few hundred metres from one another. ${ }^{3}$ In accordance with national policies, the network of primary services in the Caia district has mainly developed since the end of the Civil War and, as with all rural districts in the country, public services are mainly schools, healthcare units and wells for water supply.

\footnotetext{
${ }^{2}$ The research activity focuses on urban and land planning. Specifically Isacco Rama, former associate of the Consortium of Associations with Mozambique-CAM, through his degree thesis (2014) supervised by Professor P. Bertola and Professor C. Diamantini, developed a project proposal for implementation of the Plano Distrital de Uso da Terra, PDUT (District Land Use Plan) for Caia offering the district a tool for improving the service delivery system along the Gamba Deve-Licoma axis.

${ }^{3}$ Data relating to the population distribution is contained in the PDUT_-Plano de Uso da Terra Caia (District Land Use Plan) 2012.
} 


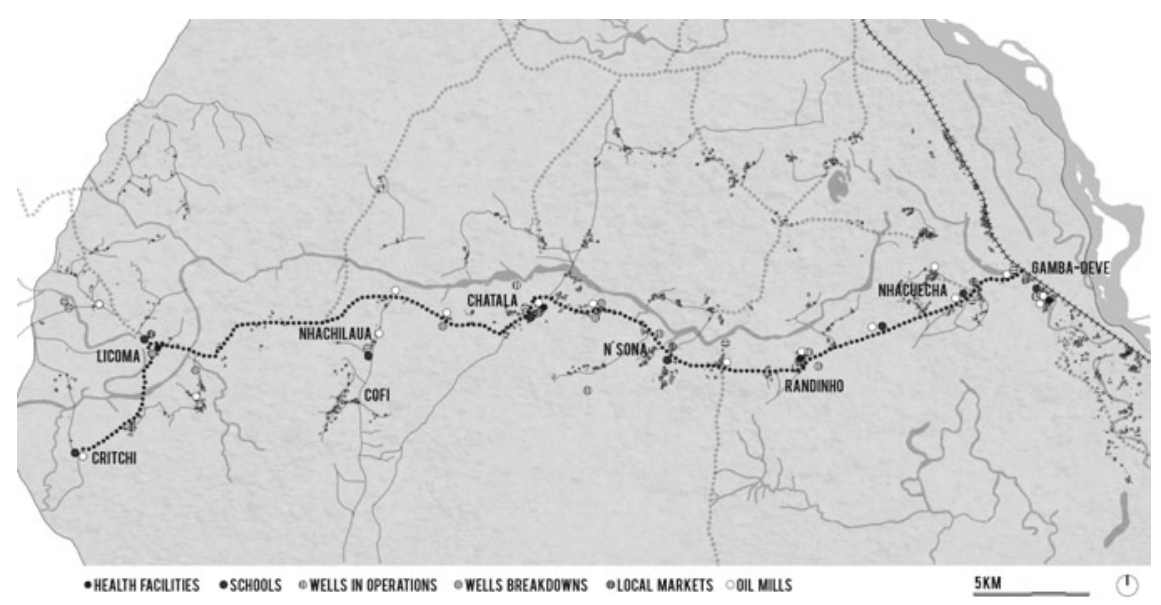

Fig. 1 Service supplying system along the Gamba Deve-Licoma axis

Alongside these, there are some activities run by private companies, such as the mills (electric or diesel-run) and the markets. The coverage of the services is not homogeneous in the district territory, and it is mostly concentrated in the more densely populated areas, in proximity to the Vilas, the major axis and the infrastructural networks between Caia and Sena; in rural areas, on the other hand, where housing dispersion in the area is highly dispersed, the network of services, whether they are public or private, is unable to satisfactorily cover the needs of the population. Moreover, the theme of the relationship between the city and the countryside, as well as the evolution of the building pattern associated with these, is fundamental to understand the socio-economic dynamics of the area studied. Indeed, while there is never a clear dualism between urban, structured and settled centres and the surrounding countryside, it is common to find simultaneous and mutually interfering development of the two realities which have a strong tendency to overlap, with the city often being a large rural settlement and the countryside taking on the typical infrastructural characteristics typical of a city.

For this reason, the revival of certain local morphological features, such as the organisation of rural areas in clusters, permits consideration of each centre as a place for trade support services, support for agricultural production, distribution and preservation of agricultural and livestock products, as well as a health centre where the minimum provision of assistance, which is guaranteed in every area, work alongside organised structures found only in larger centres.

In this traditional organisational system markets, schools, health centres and wells, they not only constitute essential services to the life of the rural population but also become genuine community centres, around which the primary settlement is organised. 


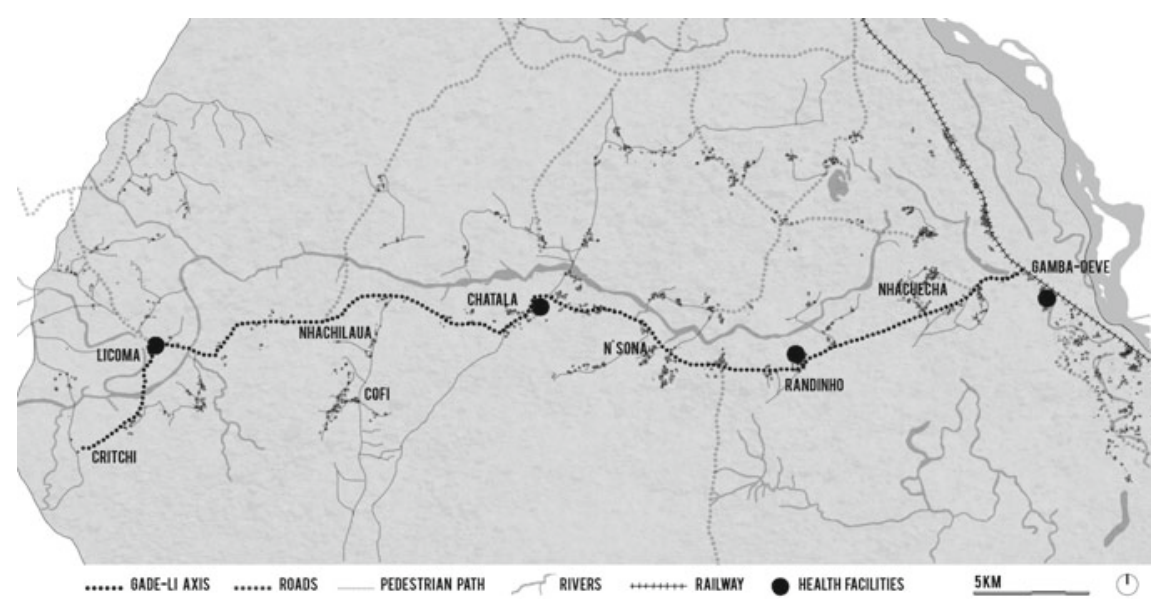

Fig. 2 Network of rural health centres along the Gamba Deve-Licoma axis

The local markets, for example, constitute for much of the population the only access to basic goods such as salt, soap, oil, clothing and local agricultural products. They are mainly located in the larger inhabited centres and in the area in question they are located in Gamba Deve, Nhacuecha, N'Sona, Chatala, Licoma and Critchi. As for the network of rural health centres (Fig. 2), this is organised on three levels: the Posto de Saude, a primary healthcare service designed to ensure an appropriate distribution of pharmaceutical and equipped to deal with the simplest of emergencies; the Centro de Saude, the intermediate circle of the rural health network, staffed by qualified healthcare personnel; finally, the Hospital Rural, a facility generally found in the district capital and divided into different departments, including surgery. Along the considered axis, the Centro de Saude (health centres) are located in Gamba Deve, Randinho, Chatala and Licoma, while the only structure in Randinho is a Posto de Saude (smaller health centre) (Rama 2013).

Similarly, the building pattern of the mudzi, either isolated or combined, meeting to the traditional housing needs of this specific context and identified as a building principle for new services too, together with the use of local resources and the involvement of the local population in the operational and constructive phase, outlines a strategy applicable to different areas, on a case to case basis, while at the same time maintaining a distinctive typological and representational form.

In particular, in this specific context, certain traditional building characteristics have been identified that reflect a specific usage of the land and space; indeed, apparently arranged at random, the Mudzis reflect, in reality, a very precise cultural and community hierarchy. Each such building is the result of entirely spontaneous activity, but has the immediate purpose of representing the size and importance of the household, basing its construction on the use of local material, which is easily available and affordable, such as wood, raw earth mixed with water, straw and bamboo. 
Therefore, by refusing a fragmentary vision with sporadic opportunities for intervention and a conception of a large-scale (all-encompassing but sometimes abstract) transformation of the territory, this project adopted a working strategy for building units consistent with an appropriate scale where it was possible to find specific relationship of coherence with the scale of the natural landscape, linked to individual needs for urban or rural transformation with local morphological features and building characteristics. Thus, the various area of production and social reorganisation are revisited in this African context proposing coordination between ad hoc interventions and infrastructural reorganisation of urban areas and agricultural sectors, through a minimum provision of health and social welfare facilities.

\section{Social Welfare Prototyping Experimentation}

Recent experiments aimed tackling crises in countries affected by emergencies have relied on the development of a standardised quantitative model due to the urgent need to pre-empt critical situations minimising, however, the interest in the construction quality of the space, and therefore, robbing of it the compositional and figurative themes that define the architectural artefact through details. Here, we are seeking to understand how the production potential of modern industry may be evaluated in a critical standardisation process in which it is also possible to reconsider certain principles inspired by "quality in quantity" (Semerani 1978), in other words a more flexible production capacity to meet the need for provision of temporary constructions with greater structural complexity and, therefore, in the architectural terms, compatible, not only constructionally but also figuratively and environmentally and aesthetically with the circumstance in which we found ourselves operating.

The project addresses the compositional aspects that define the architectural space of the prototype derived from the investigation of the sociocultural aspects, the needs of the communities and analysis of traditional buildings (Neutra 1948). One of the fundamental aspects of this project is the union between form and materials, reflected in the design experimentation, in which form viewed as the act that precedes the design phase, is coherently expressed in its entirety.

Design of care, cultural and social structure requires a multidisciplinary approach in order to organise the building in a way that is over the time. The requirements in terms of the flexibility, modularity, aggregation and reversibility of the prototype are, therefore, a key element in responding to rapid changes and the needs of the population (Kleczkowski et al. 1985).

The prototype integrates health and social care characteristics with the economical, social, cultural and institutional conditions seeking exemplary social, functional and representational qualities within historical architectural experience.

To illustrate the proposed strategy, a multifunctional prototype was tested by a group of students who have worked with the ADL Group-Architectural Design 
Laboratory. ${ }^{4}$ The prototype, designed with modular elements easily adaptable to other very isolated contexts, consists of a simple low-cost structure easily implemented for services and health and social care provisions (Staib et al. 2010). The aim is, therefore, to create a multi-purpose structure as a focal meeting point for the local community in question.

The project defines its typological and representational choices through interpretation of the traditional architecture of the analysed context, namely the popular local dwelling (the mudzi), which consists of a group of small buildings (palhotas), arranged around a large circular open space (Nicchia 2011)—using the architect John Hejduk's studies of decomposition of space.

The flexibility of the space is obtained here through the decomposition of the a square (Fig. 3), the result of careful analysis of the complexity of Hedjuk's living spaces. Form and organisation of space, representation and reciprocity are elements of reflection for that author. In his three "Diamond House" designs, Hejduk is inspired by the paintings of Mondrian, using rotation of the square and on horizontal and vertical lines, which are transposed into his projects as dividing partitions. The partition becomes the modular element that makes up the healthcare and social spaces facility. These elements enable us to achieve considerable complexity, being arranged around a central space as the unifying core of the surrounding elements, a reference to the palhotas of popular local architecture.
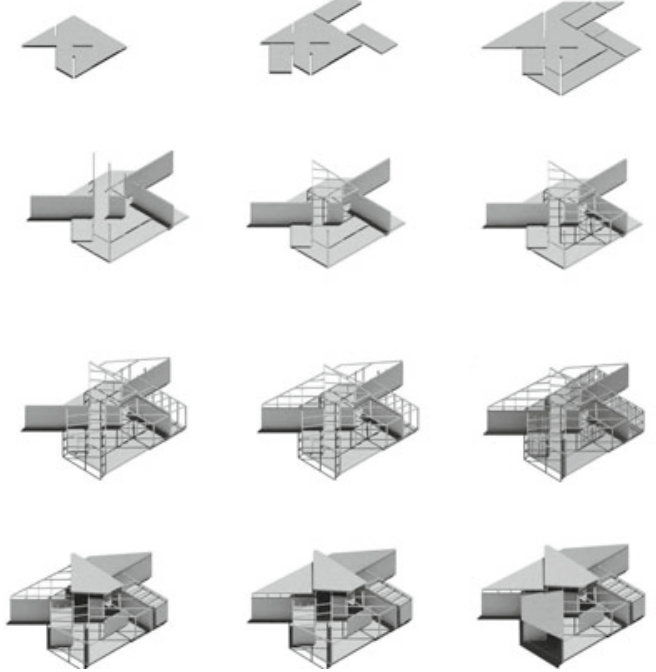
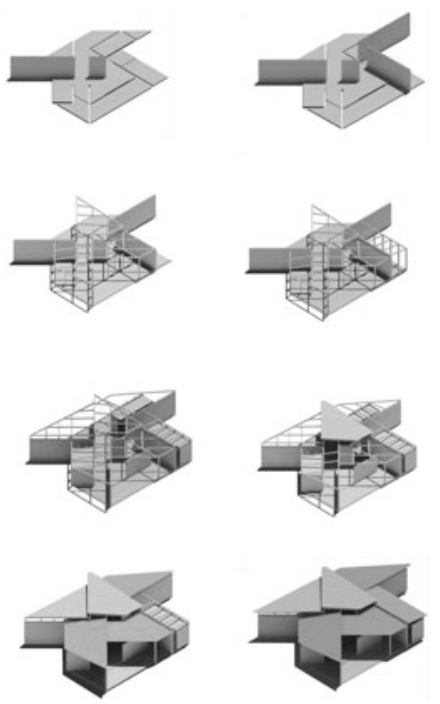

Fig. 3 Compositional process of the prototype through decomposition of a square

\footnotetext{
${ }^{4}$ The prototype was made in 2015 in collaboration with the students M. I. Guin, F. Martellono, F. Menici.
} 
The roof, consisting of a pitched system supported by a modular beam that connects the various components of the prototype, reflects the complexity of the internal space. Thus, the system of hierarchies within the facility is highlighted, rendering the pivotal role of the central space, reminiscent of the mudzi clear and legible. The modularity of the prototype becomes the guideline for building the relationships between space and structure, defining the compositional process behind the project (Ceccarini 1989). The sustainability of the prototype is characterised by low construction costs, availability of construction materials and easy of construction. The load-bearing structure is made entirely of wood, a material that is easy to assemble thanks to its modularity and the partitions are covered with raw earth bricks that reinforce the structure (Fig. 4).

\section{Conclusion}

In conclusion of this journey, to return to some of the issues mentioned at the beginning, we would like to clarify the role of the versatility, reversibility and the temporary nature of the design, less in its authorial dimension than in a more conceptual one, and therefore, at least open to generalisation with regard to the various implementation scales; for example, the coherence between objectives and the means developed to implement them; between new figuration and contextual architecture; or even regarding construction and sustainable forms of incentives for the use of local resources and so on. This position is supported by design dimension that is not an exclusive finished product, but rather tends to open up its formalisation potential through a procedure oriented more towards prototyping than towards the author's model.

Guido Canella clarifies this position in his famous essay on building motivations and the experimental design of the Milanese theatre system. In his interpretation of architectural prototyping, Canella seeks to illustrate those features of experimentation with form, alluding to the prototype as a design synthesising distributive and geometric — and therefore also typological—conception tied to particular functional and social life system. He defines prototypes as "educational projects", indicating their instrumental aspect since they will occupy the final pages of some theoretical paper. However, the term "educational" perhaps also, unconsciously, signifies a selfcritical reserve concerning the degree of simplicity, or if you will, approximation of architectural expression (Canella 1966).

The prototype is an architectural idea and must be equipped with a deep structure conception, as a part of the typological research. The prototype engages the limits of an early theoretical reflection, which precedes the actual act of design, contemplating 

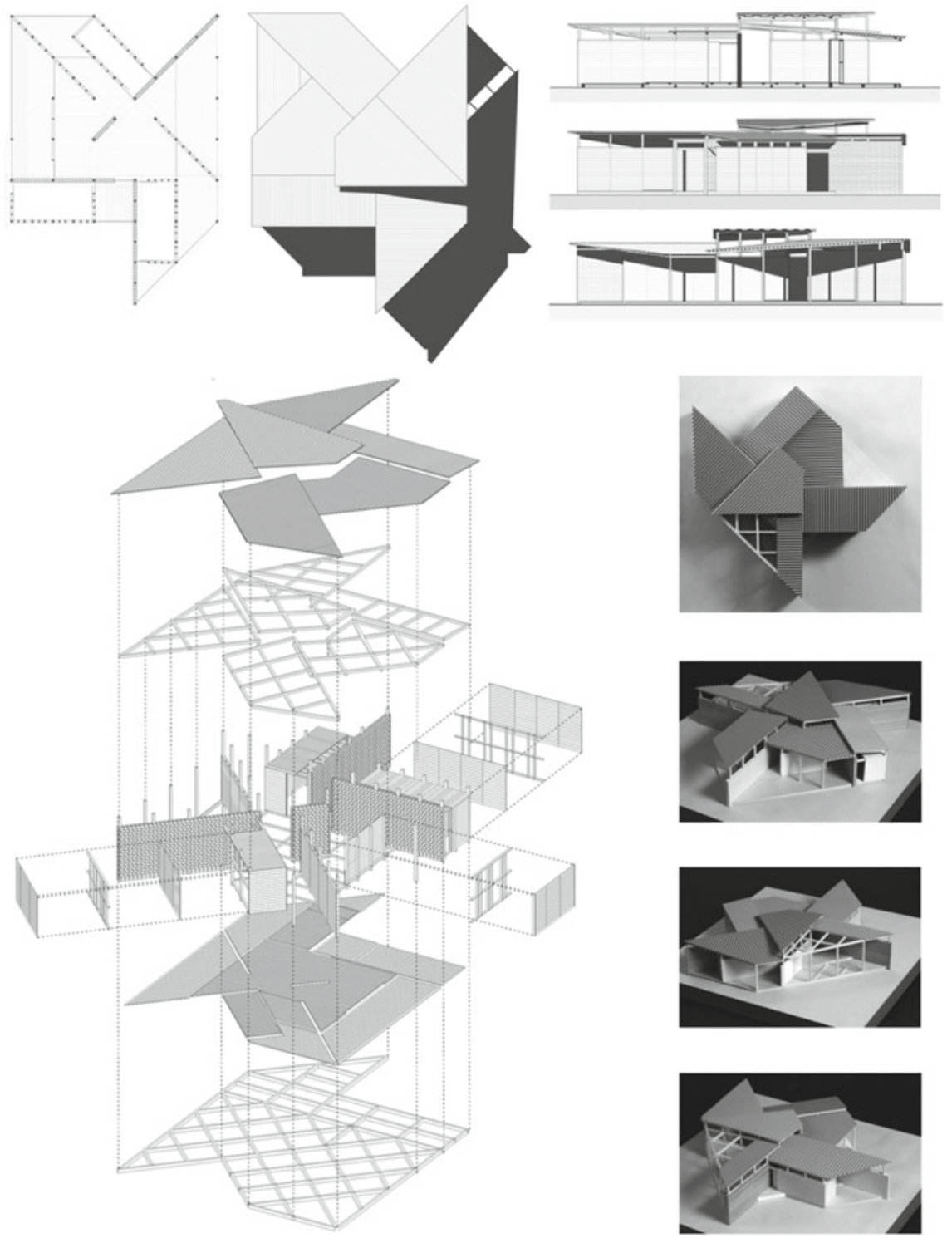

Fig. 4 Experimental design 
possible scenarios that may be viewed as the abacus of possible solutions compatible with different contextual conditions. The underlying objective is to define a method of prototyping capable of assuming the degrees of versatility required by the contingency of the intended use, but which can also encapsulate an idea that envisages coherent typological and representational choices (Canella 1978). For this reason, we have chosen to work through a prototype rather than a defined design in an attempt to render as clear as possible the principles of generalisation as opposed to the specific contextual requirements to which a design tends to by its nature. On the other hand, the same envelope can potentially be designed to acquire solar energy to control shading and views, to insulate for natural and controlled ventilation, for natural and artificial lighting, to store water, etc. All essential requirements which, however, adhere to a principle of good practice, which it is believed, should be developed according to the specific design preferences that deviate from the generalisation conditions required here in order to make the adopted procedure transmissible. A unique construction system, therefore, is able to work for different intended uses, simply adapting its structural geometry to the function and modulating the space to the form's requirements. Not only that. The objective also relates to the design of typological versatility of the architectural artefact which, through an appropriate examination of distribution choices, is able to combine and overlap various activities compatible with those relating to welfare and health (education, education and training) in its daily operating cycle. And here, too, the generalisation aspects may subsequently, on a case by case basis, be adapted to the social and localisation needs of the context. In this way, from the standard minimum building structure capable of offering, for example, care and services to the most remote rural communities (doctor's visits, immunisations, pre-natal and post-natal care, nutrition centres, etc.), this proposal aims to investigate how this building principle could be generalised for more complex functions and spaces and for the associated activities and tasks necessary, in each case.

\section{References}

Canella G (1966) Il sistema teatrale a Milano. Dedalo, Bari, p 165

Canella G (1978) Assumere l'emergenza che non finisce. Hinterland 5-6:2-3

Ceccarini I (1989) Composizione modulare: grammatica della progettazione. U. Hoepli, Milan, pp $73-77 ; 157-162 ; 274-275$

Chizzoniti D, Beggiora K, Cattani L, Moscatelli M (2014) Health post: a sustainable prototype for the third world. World Acad Sci Eng Technol Int J Civ Architectural Sci Eng 8(4):56-61

Falasca CC (2000) Architetture ad assetto variabile: modelli evolutivi per l'habitat provvisorio. Alinea, Florence, pp 13-29; 116

Kleczkowski BM, Montoya-Aguilar C, Nilsson NO (1985) Approaches to planning and design of health care facilities in developing areas, vol 5, no 91. Division of Strengthening of Health Services, World Health organization, Geneva, pp 31-33, 77-106

Neutra R (1948) Arquitetura social em paises de clima quente. Gerth Todtmann, São Paulo 
Nicchia R (2011) Planning African rural towns. The case of Caia and Sena, Mozambique. University of Trento, Department of Civil, Environmental and Mechanical Engineering

Novi F (1994) Criteri e principi per la costruzione facilitata e l'autocostruzione con l'impiego di processi costruttivi, di strumenti e di tecnologie innovative: relazione finale del triennio di ricerca. BE-MA, Milan, pp 150-160; 176-184

Rama I (2013) Sviluppo Rurale e Assetto del Territorio in Contesti in Via di Sviluppo: un Progetto Attuativo del Plano de Uso da Terra in un Distretto Rurale del Mozambico. University of Trento, Department of Civil, Environmental and Mechanical Engineering

Semerani L (1978) Ricostruzione senza Rinascita. Hinterland 5-6:4-8

Staib G, Dörrhöfer A, Rosenthal M (2010) Atlante della progettazione modulare: elementi, sistemi, nuove tecnologie. UTET Technical Sciences, Turin, pp 25-30; 43-44

Open Access This chapter is licensed under the terms of the Creative Commons Attribution 4.0 International License (http://creativecommons.org/licenses/by/4.0/), which permits use, sharing, adaptation, distribution and reproduction in any medium or format, as long as you give appropriate credit to the original author(s) and the source, provide a link to the Creative Commons license and indicate if changes were made.

The images or other third party material in this chapter are included in the chapter's Creative Commons license, unless indicated otherwise in a credit line to the material. If material is not included in the chapter's Creative Commons license and your intended use is not permitted by statutory regulation or exceeds the permitted use, you will need to obtain permission directly from the copyright holder. 